Check for updates

Cite this: RSC Adv., 2018, 8, 17950

Received 5th March 2018

Accepted 9th May 2018

DOI: 10.1039/c8ra01925h

rsc.li/rsc-advances

\section{Sepiolite/CNT/SaPANI composite with stable network structure for high performance lithium sulfur batteries $\uparrow$}

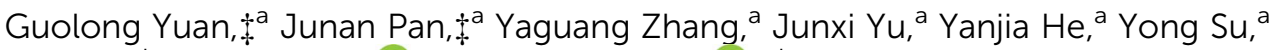 \\ Qi Zhou, ${ }^{b}$ Hongyun Jin (iD ${ }^{c}$ and Shuhong Xie (iD *d
}

Composite materials with a stable network structure consisting of natural sepiolite (Sep) powders, carbon nanotubes (CNTs) and conductive polymer (PANI) have been successfully synthesized using a simple vacuum heat treatment and chemical oxidation method, and they have been used as cathode materials for lithium sulfur batteries. It is found that Sep/CNT/S@PANI composites possess high initial discharge capacity, good cyclic stability and good rate performance. The initial discharge capacity of the Sep/CNT/ SaPANI-II composite is about $1100 \mathrm{~mA} \mathrm{~h} \mathrm{~g}^{-1}$ at 2C, and remained at $650 \mathrm{~mA} \mathrm{~h} \mathrm{~g}^{-1}$ after 300 cycles, and the corresponding coulombic efficiency is above $93 \%$. Such performance is attributed to specific porous structure, outstanding adsorption characteristics, and excellent ion exchange capability of sepiolite, as well as excellent conductivity of CNT. Furthermore, the PANI coating has a pinning effect for sulfur, which enhances the utilization of the active mass and improves the cycling stability and the coulombic efficiency of the composites at high current rates.

\section{Introduction}

Utilization of sulfur as a cathode material enables the electrochemical system of lithium-sulfur ( $\mathrm{Li}-\mathrm{S}$ ) batteries to have a high energy density of $2600 \mathrm{~W} \mathrm{~h} \mathrm{~kg}{ }^{-1} \cdot{ }^{1-3}$ Besides the large specific capacity, ${ }^{4,5}$ sulfur is also inexpensive and environmentally friendly, ${ }^{6,7}$ stimulating extensive research. However, the commercialization of the Li-S battery is challenged by the severe "shuttle effect" resulting from the dissolution of lithium polysulfide during the charge/discharge process. ${ }^{8,9}$ The repeated polysulfide shuttling causes the loss of active materials, resulting in low coulombic efficiency and low cycle life. ${ }^{10-12}$ Furthermore, the low conductivity of sulfur and $\mathrm{Li}_{2} \mathrm{~S}$ leads to poor rate capability. ${ }^{\mathbf{1 3 , 1 4}}$

To overcome these drawbacks, significant efforts have been carried out to improve the performance of Li-S battery by incorporating additives into sulfur cathodes, including carbon

${ }^{a}$ Hunan Provincial Key Laboratory of Thin Film Materials and Devices, Xiangtan University, Xiangtan, 411105 Hunan, China

${ }^{b}$ State Key Laboratory of Advanced Processing and Recycling of Nonferrous Metals, Lanzhou University of Technology, Lanzhou, 730050 Gansu, China

${ }^{c}$ Engineering Research Center of Nano-Geomaterials of Ministry of Education, China University of Geosciences, Wuhan, $430074 \mathrm{Hubei,} \mathrm{China}$

${ }^{d}$ Key Laboratory of Low Dimensional Materials and Application Technology of Ministry of Education, School of Materials Science and Engineering, Xiangtan University, Xiangtan 411105, Hunan, China. E-mail: shxie@xtu.edu.cn

† Electronic supplementary information (ESI) available. See DOI: 10.1039/c8ra01925h

\$ These authors contributed equally to this work. materials, ${ }^{15-17}$ conductive polymers ${ }^{18-20}$ and metal oxides. ${ }^{6,21}$ It was reported that carbon materials added into sulfur cathode are effective in improving the comprehensive performances of sulfur cathode, including CMK-3, ${ }^{22}$ carbon nanotubes, ${ }^{23}$ and carbon nanofibers. ${ }^{24}$ Meanwhile some conductive polymers were coated onto the sulfur cathode to reduce the dissolution of lithium polysulfides and increase the conductivity of sulfur, including polyaniline $e^{25,26}$ and polypyrrole. ${ }^{27,28}$ Metal oxides were also applied to improve the performance of $\mathrm{Li}-\mathrm{S}$ batteries, as they can effectively adsorb lithium polysulfides by chemical adsorption. ${ }^{21,29}$ Our previous study demonstrated the sepiolite/sulfur (Sep/S) composite as a promising cathode material due to its low cost and simple synthesis method. ${ }^{30}$ Indeed, the strong adsorption of sepiolite for polysulfide enabled good conversion efficiency of active material. Nevertheless, the poor electrical conductivity and impurity of nature sepiolite result in low coulombic efficiency at high current rate.

Herein, we design a network structure that can reinforce the stability of the composite by adding both carbon nanotubes (CNTs) and polyaniline (PANI) into the Sep/S matrix, forming a composite cathode denoted as Sep/CNT/S@PANI. As shown in Fig. 1, Sep/CNT/S composite was first synthesized via vacuum heating treatment method, and then followed by the chemical oxidation method to form the Sep/CNT/S@PANI composite. The composite cathode exhibits excellent electrochemical performance, especially at high current rate, since CNTs possess excellent electrical conductivity while PANI coating layer serves as a barrier to restrict the diffusion of polysulfide. 


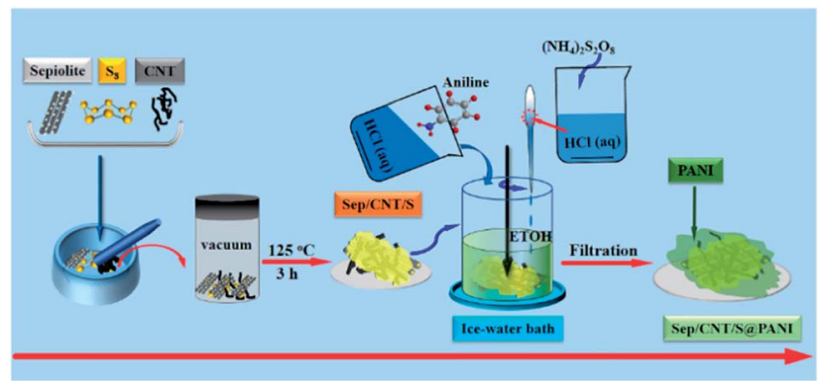

Fig. 1 Schematic of the formation process of Sep/CNT/S@PANI composite.

\section{Experimental section}

\subsection{Fabrication of Sep/CNT/S composites}

Natural sepiolite powders (Sep) were bought from a mineral processing factory in Hunan Province, China. Carbon nanotubes (CNT), sublimed sulfur (S), aniline monomers (An), ammonium persulfate $\left(\left(\mathrm{NH}_{4}\right)_{2} \mathrm{~S}_{2} \mathrm{O}_{8}\right)$, hydrochloric acid $(\mathrm{HCl})$, polytetrafluoroethylene (PTFE) and acetylene black were purchased from Sinopharm Chemical Reagent Co. Ltd. (China). All chemicals of analytical grade were used without further purification.

The Sep/CNT/S composite was prepared via a universal vacuum heat treatment method. Typically, $0.3 \mathrm{~g}$ sepiolite powders, $0.6 \mathrm{~g}$ sulfur and $0.1 \mathrm{~g}$ carbon nanotubes with mass ratio $3: 6: 1$ were mixed by the gravimetric method. The mixture was then heated under vacuum at $125{ }^{\circ} \mathrm{C}$ for $3 \mathrm{~h}$, forming the Sep/CNT/S composite.

\subsection{Fabrication of Sep/CNT/S@PANI composites}

Three Sep/CNT/S samples (each of $0.2 \mathrm{~g}$ ) were used, and each sample was mixed with $30 \mathrm{~mL}$ ethanol by ultrasonication to make them disperse uniformly. Three $15 \mathrm{~mL} 2 \mathrm{M} \mathrm{HCl}$ solutions and anilines with different weights of $0.05 \mathrm{~g}, 0.1 \mathrm{~g}$ and $0.2 \mathrm{~g}$ were mixed respectively, which were then added into the three Sep/ $\mathrm{CNT} / \mathrm{S}$ samples, followed by adding the mixture solution of $15 \mathrm{~mL} 2 \mathrm{M} \mathrm{HCl}$ with $\left(\mathrm{NH}_{4}\right)_{2} \mathrm{~S}_{2} \mathrm{O}_{8}(0.1 \mathrm{~g}, 0.2 \mathrm{~g}$ and $0.4 \mathrm{~g})$. After 12 hours stirring at ice-water bath, the dark green products were obtained through centrifugation and dried for $12 \mathrm{~h}$ at $60^{\circ} \mathrm{C}$ in vacuum. Finally, the polyaniline (PANI) layer with different amount of PANI to Sep/CNT/S composites were obtained and denoted as Sep/CNT/S@PANI-I, II, and III respectively.

\subsection{Material characterization}

The structure and composition of the composites were examined using X-ray diffraction (XRD, Rigaku D/max-2400) with $\mathrm{Cu}$ $K \alpha$ radiation $(\lambda=1.5406 \AA)$. The morphology of the synthesized composites were observed by scanning electron microscopy (SEM, Hitachi S-4800) and transmission electron microscopy (TEM, FEI Tecnai G2 F20) with energy dispersive X-ray spectroscopy (EDS). The Brunauer-Emmett-Teller (BET) surface area and pore size distributions were measured using a JWBK122W system. The infrared spectroscopy (IR, Perkin-Elmer
Spectrum One spectrophotometer) was applied to confirm the structures of composites. Thermogravimetric (TG) analysis was carried out by SDT-Q600 thermal analyzer in $\mathrm{N}_{2}$ atmosphere.

\subsection{Electrode fabrication and electrochemical test}

For positive electrode fabrications, $70 \mathrm{wt} \% \mathrm{Sep} / \mathrm{CNT} / \mathrm{S}$ composite or Sep/CNT/S@PANI-I, II and III composites, $20 \mathrm{wt} \%$ acetylene black and $10 \mathrm{wt} \%$ polytetrafluoroethylene (PTFE) binders were homogeneously mixed in an ethanol solvent under continuous magnetic stirring for $3 \mathrm{~h}$, and then the slurry was coated uniformly on an aluminum foil. The electrode was dried under vacuum at $60{ }^{\circ} \mathrm{C}$ for $12 \mathrm{~h}$. After that 2016 type coin cells were assembled in an argon-filled glove box. Lithium metal was used as a counter electrode and polypropylene membrane was used as the separator. The electrolyte was $1 \mathrm{M}$ lithium bis(trifluoromethanesulfonyl)imide (LiTFSI) dissolved in a $1: 1$ volume ratio mixture of 1,3-dioxolane and dimethoxy ethane.

Electrochemical charge-discharge and cyclic performances were measured at room temperature using a BTS-5V3A battery test system (Neware, Shenzhen, China), with the voltage range from 3.0 to $1.0 \mathrm{~V}\left(v s\right.$. $\left.\mathrm{Li} / \mathrm{Li}^{+}\right)$. Cyclic voltammetry (CV) and electro-chemical impedance spectroscopy (EIS) were tested using a CHI660D electrochemical workstation (Chenhua, Shanghai, China) over a frequency range of $1 \mathrm{MHz}$ to $0.1 \mathrm{~Hz}$, with an open-circuit AC voltage amplitude of $5 \mathrm{mV}$.

\section{Results and discussion}

The X-ray diffraction patterns of Sep/CNT/S, Sep/CNT/S@PANII, Sep/CNT/S@PANI-II and Sep/CNT/S@PANI-III are shown in Fig. 2(a), and the sharp diffraction peaks of sulfur illustrate its good crystallinity in the four composites. The diffraction peak near $27^{\circ}$ can be assigned to $\mathrm{SiO}_{2}$, which indicates the existence of sepiolite. In addition, with the increased PANI fraction (from Sep/CNT/S@PANI-I to Sep/CNT/S@PANI-III), the intensity of characteristic diffraction peaks decreases due to the relative low crystallinity of PANI. ${ }^{31,32}$

The FTIR spectrums of Sep/CNT/S composites with and without PANI coating are shown in Fig. 2(b). The absorption peaks at $1030 \mathrm{~cm}^{-1}$ and $469 \mathrm{~cm}^{-1}$ correspond to the $\mathrm{Si}-\mathrm{O}-\mathrm{Si}$ stretching. ${ }^{33}$ After coating PANI the absorption peaks corresponding to $\mathrm{Si}-\mathrm{O}$ stretching and bending of sepiolite gradually weaken, and the peaks at $789 \mathrm{~cm}^{-1}$ and $681 \mathrm{~cm}^{-1}$ and peaks at $1590 \mathrm{~cm}^{-1}$ and $1499 \mathrm{~cm}^{-1}$ are observed, which are consistent with those of the quinone ring and benzene ring of polyaniline. ${ }^{34}$ Furthermore, the absorption peaks at $1379 \mathrm{~cm}^{-1}$ and $1161 \mathrm{~cm}^{-1}$ correspond to the stretching vibration of $\mathrm{C}-\mathrm{N}$ bond in aromatic amine and $-\mathrm{N}=\mathrm{Q}=\mathrm{N}-$ bond in polyaniline, respectively. ${ }^{35}$ The characteristic peak at $505 \mathrm{~cm}^{-1}$ refers to the bending vibration of aromatic ring. Thus FTIR spectra confirms the existence of PANI in Sep/CNT/S@PANI composites. ${ }^{25,36}$ Meanwhile, the intensity of characteristic peaks of polyaniline increases with increased aniline content. ${ }^{37}$ Furthermore, thermogravimetry (TG) is used to analyze the sulfur content of the Sep/CNT/S and Sep/CNT/S@PANI composites as shown in Fig. S1, $\dagger$ suggesting that Sep/CNT/S composite and Sep/CNT/ 
(a)

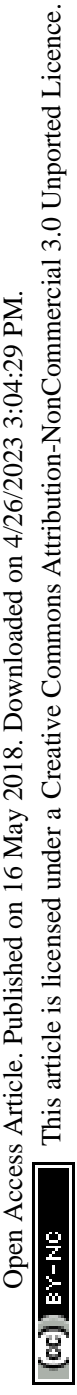

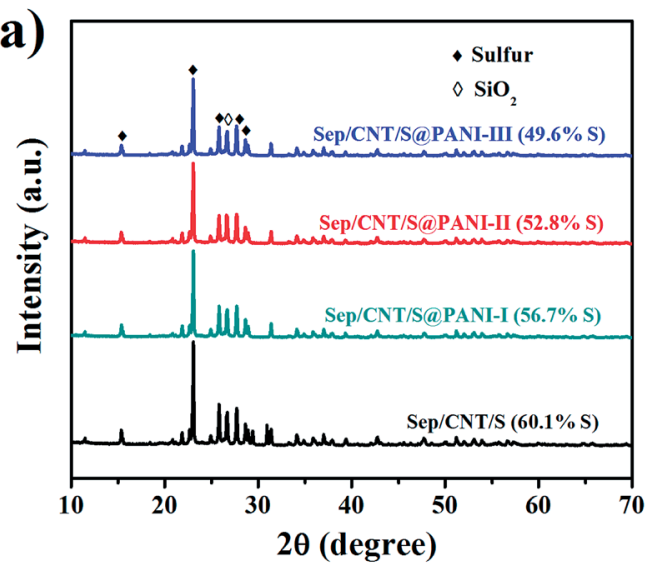

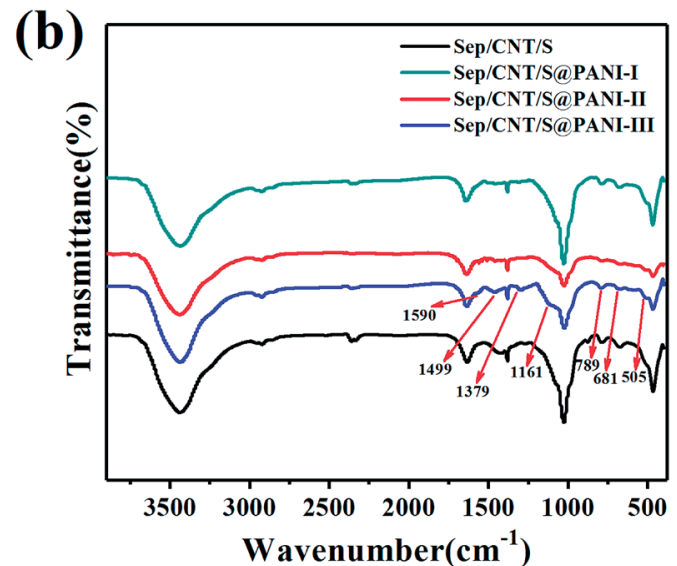

Fig. 2 (a) XRD patterns and (b) FTIR spectra of Sep/CNT/S, Sep/CNT/S@PANI-I, II and III composites.
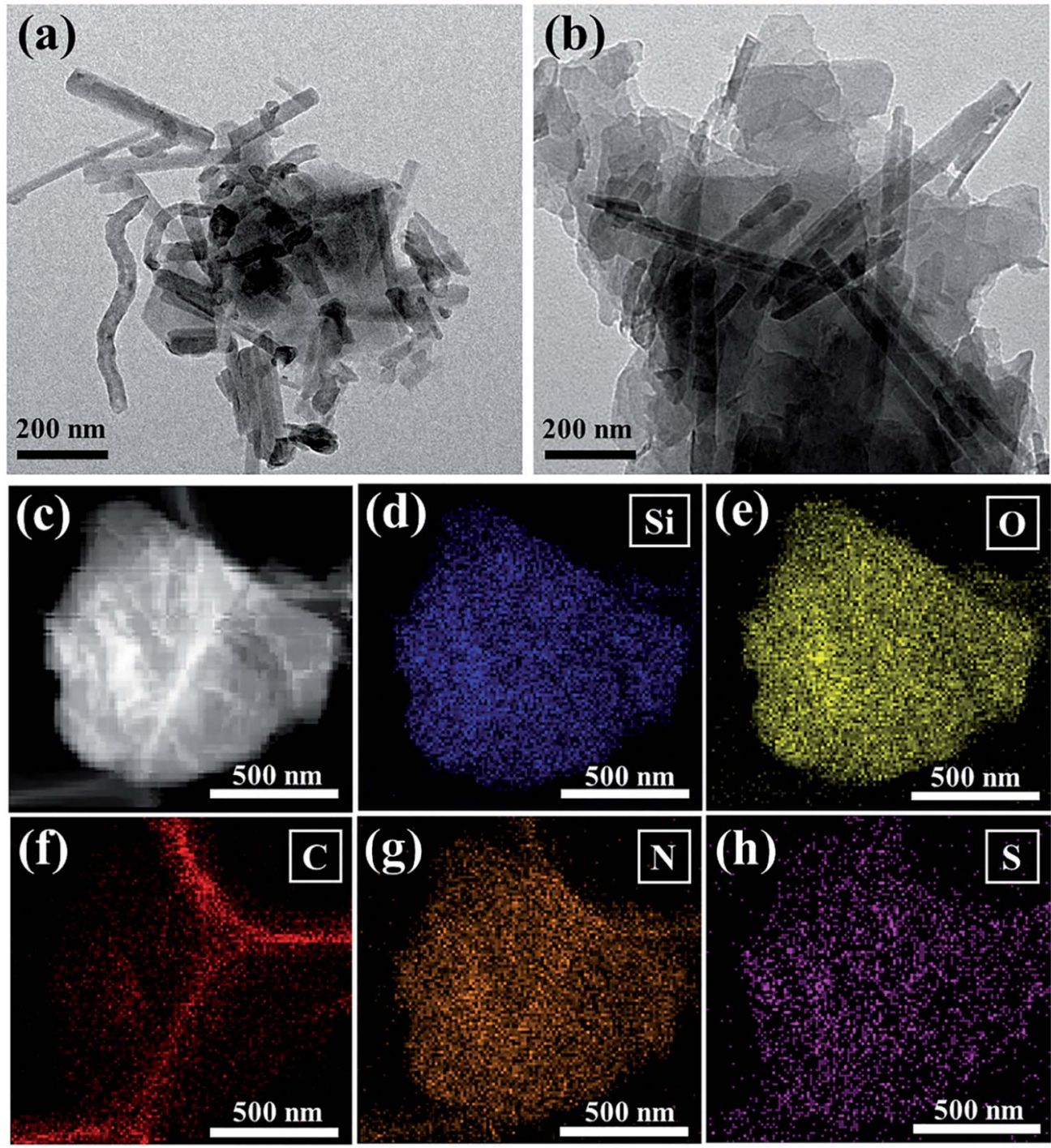

Fig. 3 TEM image of (a) Sep/CNT/S; (b) Sep/CNT/S@PANI-II; (c) bright-field TEM image and corresponding elemental mappings of (d) silicon, (e) oxygen, (f) carbon, (g) nitrogen and (h) sulfur for the as-synthesized Sep/CNT/S@PANI-II composite. 

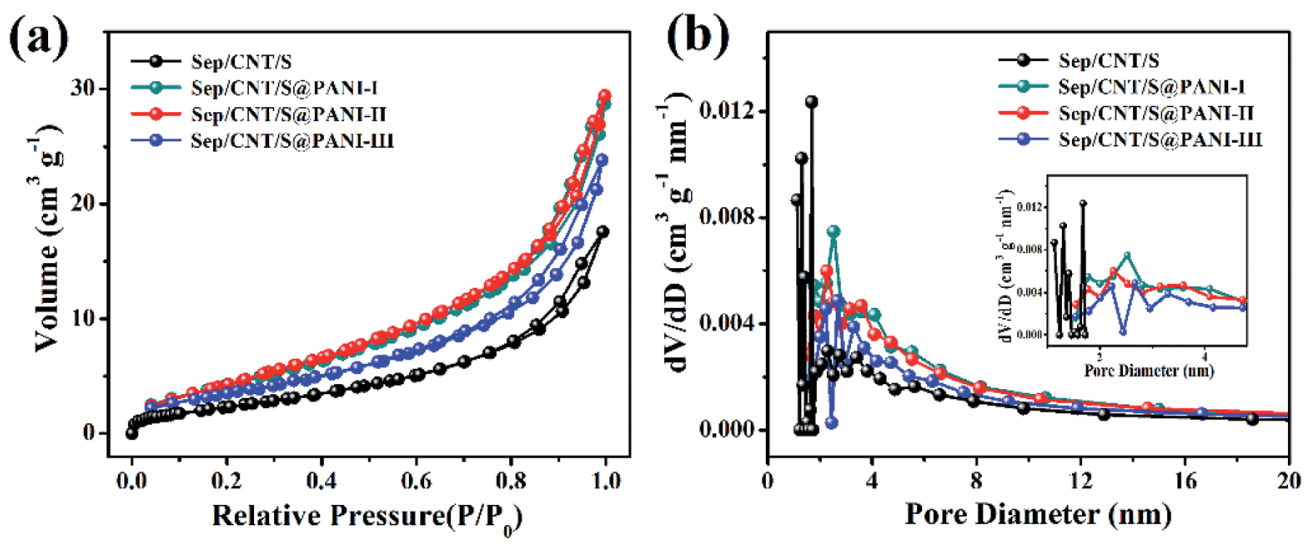

Fig. 4 (a) BET surface area and (b) pore size distribution of Sep/CNT/S and Sep/CNT/S@PANI-I, II and III composites.

S@PANI-I, II and III composites contain $60.1 \mathrm{wt} \%, 56.7 \mathrm{wt} \%$, $52.8 \mathrm{wt} \%$ and $49.6 \mathrm{wt} \%$ of $\mathrm{S}$, respectively. The differences between Sep/CNT/S composite before and after coating PANI indicate the corresponding mass percent of PANI in the Sep/ CNT/S@PANI-I, II and III composites are $3.4 \mathrm{wt} \%, 7.3 \mathrm{wt} \%$ and $10.5 \mathrm{wt} \%$, respectively.

The morphology of Sep/CNT/S and Sep/CNT/S@PANI-II composites are characterized by TEM with EDS, as shown in Fig. 3(a) and (b). It is observed that the network structure of Sep/ CNT/S composite are composed of short sepiolite fibrous bundles with length in the range of $200 \mathrm{~nm}$ to $1 \mu \mathrm{m}$, as well as bended carbon nanotube with length around $1 \mu \mathrm{m}$, and the surfaces of sepiolite and CNTs are covered with sulfur. After PANI is coated on the surface of Sep/CNT/S composite, the network structure remains and aggregation appears due to the viscosity of PANI as seen in Fig. 3(b). Comparing the images of the three kinds of Sep/CNT/S@PANI composites in Fig. 3, S2 and $\mathrm{S} 3 \uparrow$ carefully, it is observed that the thickness of PANI coating is inhomogeneous, and the three dimensional network structure stability increase with increasing PANI content moderately, and excessive PANI coating reduce the surface area and the effective pore numbers due to aggregation. Moreover, the element distributions of $\mathrm{Si}, \mathrm{O}, \mathrm{C}, \mathrm{N}$, and $\mathrm{S}$ in Fig. 3(c)-(h) are uniform in the Sep/CNT/S@PANI-II composite. The Si element is ascribed to sepiolite, while the $\mathrm{O}$ element is from both polyaniline (PANI) and sepiolite, whose area is slightly larger than that of Si element. The C element arises from CNT and TEM sample substrate. Concentration of $\mathrm{N}$ element is relatively high at the edge of Si element, suggesting that PANI layer covers the Sep/CNT/S composite. The elemental mapping of S confirms that the sulfur is dispersed uniformly. These results demonstrate that PANI has been successfully deposited on Sep/CNT/S composite..$^{38}$ Since the oxidation reactions can only occur at the Sep/CNT/S interface during charging/discharging process, the highly uniform distribution of PANI coating can increase the contact area between PANI and the electrolyte, and hence increase the number of active sites for electrochemical reaction in Li-S batteries. The TEM images of Sep/CNT/S@PANI-I and III composites are shown in Fig. S2 and S3 $\uparrow$ is the SEM images of Sep/CNT/S and Sep/CNT/S@PANI composites.
$\mathrm{N}_{2}$ adsorption and desorption isotherm was used to measure the specific surface area of the Sep/CNT/S composites without and with different content of PANI coating, as shown in Fig. 4(a). The IV type isotherm of mesoporous materials is observed, ${ }^{39}$ and the specific surface area of Sep/CNT/S increases after being coated with moderate PANI, and then decreases with further coating. Fig. 4(b) reveals the change of pore diameter before and after PANI coating, showing a homogeneous distribution of pore size. Further, Table 1 lists that the specific surface area of the Sep/CNT/S composite and Sep/CNT/S@PANII, II and III composites are $9.297 \mathrm{~m}^{2} \mathrm{~g}^{-1}, 17.515 \mathrm{~m}^{2} \mathrm{~g}^{-1}, 18.731$ $\mathrm{m}^{2} \mathrm{~g}^{-1}$ and $6.320 \mathrm{~m}^{2} \mathrm{~g}^{-1}$, respectively, and the corresponding pore volume are $0.027 \mathrm{~cm}^{3} \mathrm{~g}^{-1}, 0.044 \mathrm{~cm}^{3} \mathrm{~g}^{-1}, 0.045 \mathrm{~cm}^{3} \mathrm{~g}^{-1}$ and $0.021 \mathrm{~cm}^{3} \mathrm{~g}^{-1}$, which is consistent with the results of TEM and SEM images.

The cycling performance and coulombic efficiency of the Sep/CNT/S and Sep/CNT/S@PANI-I, II and III cathodes over 300 cycles at $2 \mathrm{C}$ rate $\left(1 \mathrm{C}=1675 \mathrm{~mA} \mathrm{~g}^{-1}\right)$ are shown in Fig. $5(\mathrm{a})$. It is observed that the first specific capacity of Sep/CNT/S composite cathode is about $800 \mathrm{~mA} \mathrm{~h} \mathrm{~g}{ }^{-1}$, smaller than $1050 \mathrm{~mA} \mathrm{~h} \mathrm{~g}^{-1}$ for

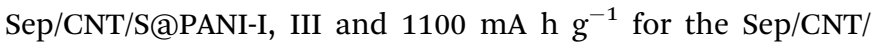
S@PANI-II cathode. Both Sep/CNT/S and Sep/CNT/S@PANI composites show larger capacity at $2 \mathrm{C}$ rate, compared to our previous study of Sep/S composite with capacity of $750 \mathrm{~mA} \mathrm{~h} \mathrm{~g}^{-1} \cdot{ }^{30}$ It is also obvious that the discharge capacity of Sep/CNT/S@PANI after 300 cycles is much better than that of Sep/CNT/S. The discharge capacity of Sep/CNT/S only remains about $200 \mathrm{~mA} \mathrm{~h} \mathrm{~g}{ }^{-1}$ after 300 cycles, while corresponding capacity of Sep/CNT/S@PANI-I, III are about $400 \mathrm{~mA} \mathrm{~h} \mathrm{~g}^{-1}$ and

Table 1 The specific surface area and pore volume value of Sep/CNT/ S and Sep/CNT/S@PANI-I, II and III composites

\begin{tabular}{lcl}
\hline Sample & $\begin{array}{l}\text { Specific surface } \\
\text { area }\left(\mathrm{m}^{2} \mathrm{~g}^{-1}\right)\end{array}$ & $\begin{array}{l}\text { Pore volume } \\
\left(\mathrm{cm}^{3} \mathrm{~g}^{-1}\right)\end{array}$ \\
\hline Sep/CNT/S & 9.297 & 0.027 \\
Sep/CNT/S@PANI $(4: 1)$ & 17.515 & 0.044 \\
Sep/CNT/S@PANI $(2: 1)$ & 18.731 & 0.045 \\
Sep/CNT/S@PANI $(1: 1)$ & 6.320 & 0.021
\end{tabular}


(a)

.
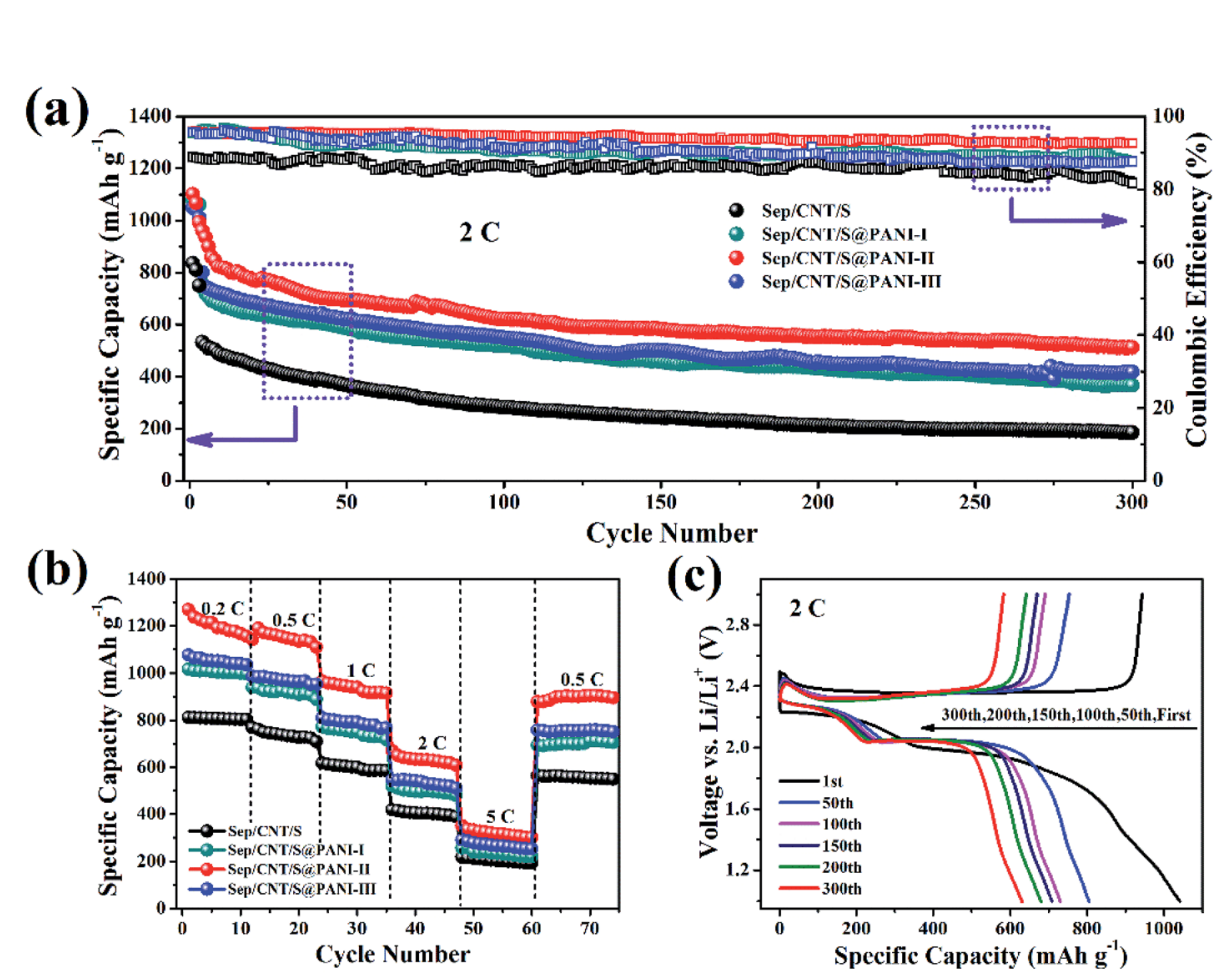

Fig. 5 (a) Cycling performance and the responding coulombic efficiency of Sep/CNT/S composite, Sep/CNT/S@PANI-I, II and III composites under big density of 2C; (b) rate capability of Sep/CNT/S composite and Sep/CNT/S@PANI-I, II and III composites under different discharge rate; (c) galvanostatic discharge-charge curves for the Sep/CNT/S@PANI-II composite at 2C discharge rate.

$450 \mathrm{~mA} \mathrm{~h}^{-1}$ respectively. In particular, the discharge capacity of Sep/CNT/S@PANI-II is the best among the four composites,

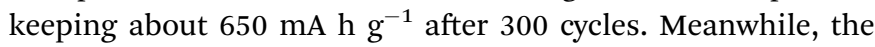
coulombic efficiency of Sep/CNT/S cathode is around $85 \%$, and corresponding value of Sep/CNT/S@PANI-I, II and III cathodes are around $89 \%, 93 \%$ and $90 \%$. The rate capability of Sep/CNT/S composite and Sep/CNT/S@PANI-I, II and III composites under different discharge rate is shown in Fig. 5(b), increasing from $0.2 \mathrm{C}$ to $5 \mathrm{C}$ by five steps and then decreasing to $0.5 \mathrm{C}$ finally. It is obvious that the rate capacities of Sep/CNT/S composite with PANI coating is much better than that of Sep/CNT/S. In particular, Sep/CNT/S@PANI-II composite possesses discharge capacity around $1270 \mathrm{~mA} \mathrm{~h} \mathrm{~g}{ }^{-1}$ under $0.2 \mathrm{C}$, and maintains a high value of $1000 \mathrm{~mA} \mathrm{~h} \mathrm{~g}^{-1}$ at $1 \mathrm{C}, 700 \mathrm{~mA} \mathrm{~h} \mathrm{~g}^{-1}$ at $2 \mathrm{C}$, and keeps $400 \mathrm{~mA} \mathrm{~h} \mathrm{~g}^{-1}$ at $5 \mathrm{C}$. When the current density returns to
$0.5 \mathrm{C}$, the discharge capacity recovers the high value around $1100 \mathrm{~mA} \mathrm{~h} \mathrm{~g}{ }^{-1}$. These indicate that the Sep/CNT/S@PANI cathode has an excellent high rate discharge capacity. Fig. 5(c) shows the charge-discharge curves at different cycles for Sep/ CNT/S@PANI-II cathode under 2C rate. Combining Fig. 5(c) with the corresponding first charge-discharge curves of the four kinds of samples at $0.2 \mathrm{C}$ rate in Fig. 6(a), it is obvious that there are two clear discharge plateaus in the first charge-discharge curves, where the high voltage platform is around $2.30 \mathrm{~V}$ and the low voltage platform is around $2.10 \mathrm{~V}$, which represents the $\mathrm{S}_{8}$ transformed into lithium polysulfides and the polysulfides transformed into the $\mathrm{Li}_{2} \mathrm{~S}_{2}$ and $\mathrm{Li}_{2} \mathrm{~S}$, respectively. ${ }^{40,41} \mathrm{As}$ seen in Fig. 5(c), the discharge capacities are 1085, 810, 760, 720, 685, and $650 \mathrm{~mA} \mathrm{~h} \mathrm{~g}{ }^{-1}$ at cycle number 1, 50, 100, 150, 200, 300, respectively.

\section{(a)}

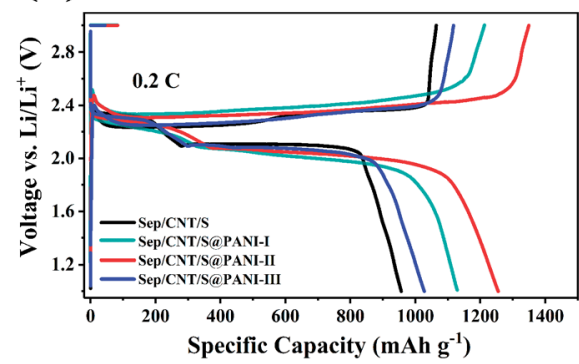

(b)

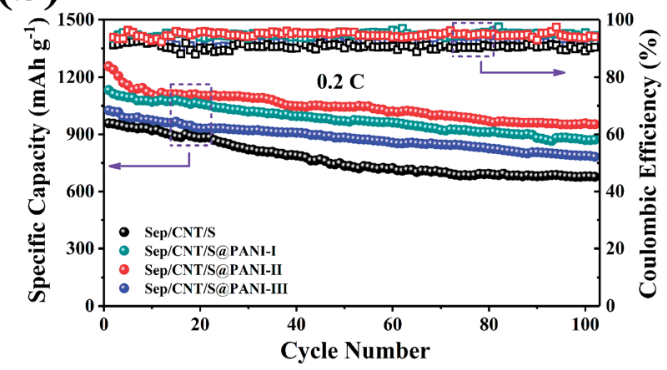

Fig. 6 (a) First discharge-charge curves for the Sep/CNT/S composite and Sep/CNT/S@PANI-I, II and III composites at 0.2C rate; (b) cycling performance and the responding coulombic efficiency of Sep/CNT/S composite, Sep/CNT/S@PANI-I, II and III composites at 0.2C rate. 
The cycling performance of the four kinds of composites under $0.2 \mathrm{C}$ rate is shown in Fig. 6(a). The first discharge capacity of Sep/CNT/S composite at $0.2 \mathrm{C}$ rate is $958.2 \mathrm{~mA} \mathrm{~h} \mathrm{~g}^{-1}$ and remains $678.6 \mathrm{~mA} \mathrm{~h} \mathrm{~g}^{-1}$ after 100 cycles, the corresponding coulombic efficiency is around $84.5 \%$. Meanwhile, the first discharge capacity of Sep/CNT/S@PANI-I, II and III composites at $0.2 \mathrm{C}$ rate are $1026.2,1132.6$ and $1256.3 \mathrm{~mA} \mathrm{~h} \mathrm{~g}^{-1}$, remains 787.8, 869.9 and $958.5 \mathrm{~mA} \mathrm{~h} \mathrm{~g}^{-1}$ after 100 cycles, the corresponding coulombic efficiency are around $88 \%, 92.5 \%$ and $90 \%$ respectively. The results show that the Sep/CNT/S composite with the PANI coating has good cycling performance at low current density 0.2C, especially the Sep/CNT/S@PANI-II composite.

Fig. 7(a) and (b) shows the cyclic voltammograms of Sep/ CNT/S cathode and Sep/CNT/S@PANI-I, II and III cathodes in a voltage range between 1.0 and $3.0 \mathrm{~V}$ before the first cycle and after 300 cycles at $2 \mathrm{C}$ with a scanning speed of $0.1 \mathrm{mV} \mathrm{s}^{-1}$. The peak potential of $\mathrm{CV}$ curves for the four composites before $1^{\text {st }}$ cycle is similar, and both the Sep/CNT/S composite and Sep/ CNT/S@PANI-I, II and III composites have two cathodic reduction peaks around $2.25 \mathrm{~V}$ and $2.0 \mathrm{~V}$ and an anodic oxidation peak around $2.60 \mathrm{~V}$. The first peak around $2.25 \mathrm{~V}$ is attributed to the elemental sulfur converted into long chain lithium polysulfides $\left(\mathrm{Li}_{2} \mathrm{~S}_{n}, 4 \leq n \leq 8\right)$, while the peak around $2.0 \mathrm{~V}$ corresponds to the process of the long chain lithium polysulfides deoxidized into short chain lithium polysulfides $\left(\operatorname{Li}_{2} \mathrm{~S}_{n}, n<4\right)$ and solid lithium sulfide $\left(\mathrm{Li}_{2} \mathrm{~S}\right)$, respectively. The corresponding oxidation peak around $2.6 \mathrm{~V}$ represents the process that the lithium polysulfides and $\mathrm{Li}_{2} \mathrm{~S}$ are oxidized into elemental sulfur. ${ }^{42,43}$ It is obvious that the instantaneous current of cathodic reduction and anodic oxidation peaks for Sep/CNT/ S@PANI-I, II and III cathodes are higher than that of Sep/ $\mathrm{CNT} / \mathrm{S}$, which indicates that the active masses of Sep/CNT/ S@PANI-I, II and III cathodes are larger than that of Sep/CNT/ $\mathrm{S}$, especially the Sep/CNT/S@PANI-II cathode. It is also observed that after $300^{\text {th }}$ cycles the cathodic reduction and anodic oxidation peaks with PANI coating are still obvious, which indicates that the Sep/CNT/S@PANI-I, II, and III cathodes are more stable than that of Sep/CNT/S after 300 cycles. ${ }^{44}$

Fig. 7(c) and (d) represent the EIS behaviors of Sep/CNT/S cathode and Sep/CNT/S@PANI-I, II and III cathodes before cycle and after 300 cycles, respectively. As seen in Fig. 7(c), the charge transfer resistances of Sep/CNT/S@PANI-I, II and III cathodes are smaller than that of Sep/CNT/S cathode owing to the good interface contact and conductivity of PANI, the corresponding value of Sep/CNT/S and Sep/CNT/S@PANI-I, II and III composites are 204.2, 166.2 and $148.7 \Omega$ respectively. After 300 cycles as shown in Fig. 7(d), the four electrodes exhibit obviously decreased resistances compared with the corresponding fresh cells, especially in the Sep/CNT/S@PANI-II cathode, the corresponding resistance $\left(R_{\mathrm{ct}}\right)$ of Sep/CNT/S and Sep/CNT/ S@PANI-I, II and III composites are 89.8, 76.3, 39.4 and 72.8 $\Omega$ respectively. The decrease of impedance may be due to the formation of some conducting interfacial layer, favoring the electrochemical stability of the system and resulting in the reduction of charge transfer resistance as the number of cycles

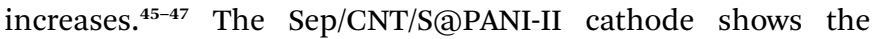
smallest charge transfer resistance after 300 cycles, which is consistent with the results in Fig. 5. However, the Sep/CNT/ S@PANI-II and III composites appear another semicircle in
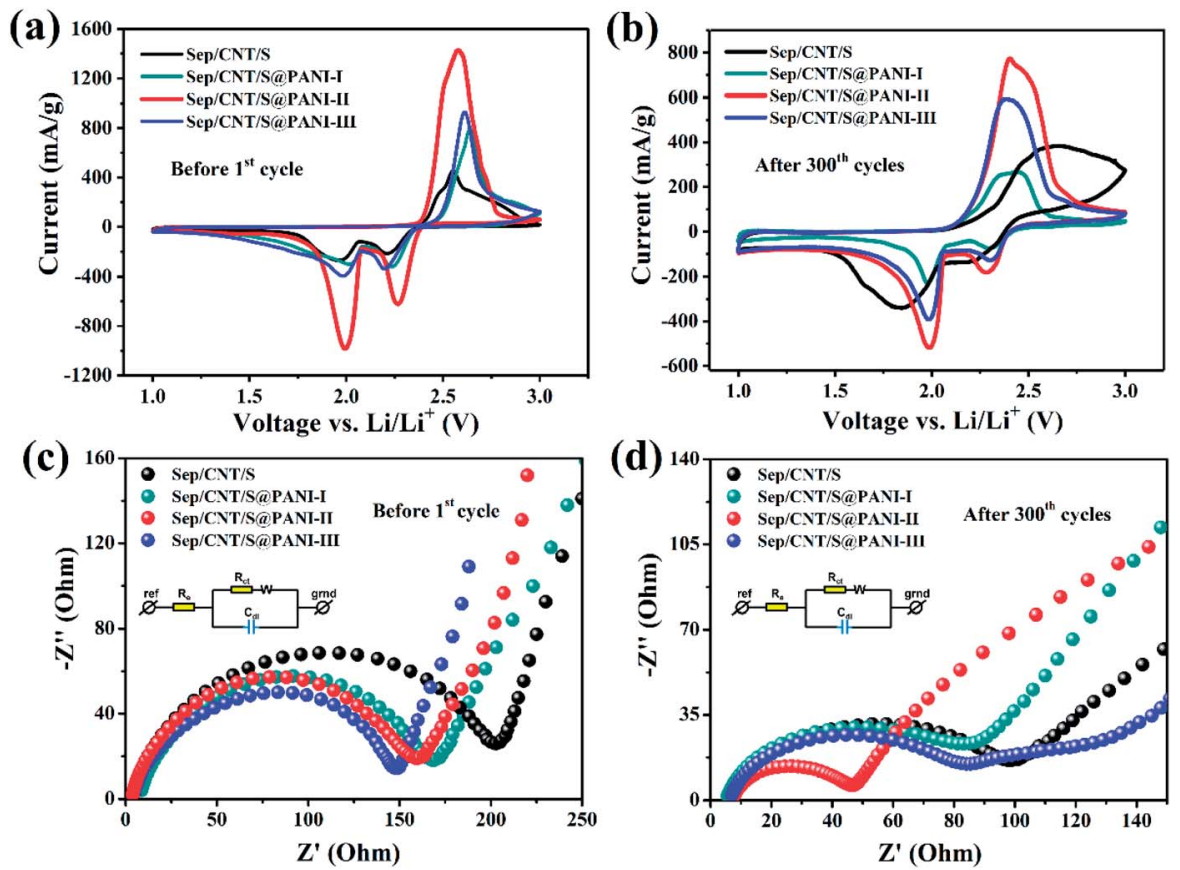

Fig. 7 (a) The cyclic voltammetry curves of the Sep/CNT/S composite and Sep/CNT/S@PANI-I, II and III composites before the first cycle and (b) after 300 cycles with a scan rate of $0.1 \mathrm{mV} \mathrm{s}^{-1}$ in a voltage range between 3.0 and $1.0 \mathrm{~V}$ vs. Li metal reference electrode at $2 \mathrm{C}$ discharge rate; (c) EIS of the Sep/CNT/S cathode and Sep/CNT/S@PANI-I, II and III cathodes before the first cycle and (d) after 300 cycles at $2 \mathrm{C}$ discharge rate and fully charged to $3 \mathrm{~V}$. 
medium frequency region, that is similar with the electrochemical impedance spectra (EIS) in the reported literature, ${ }^{48}$ which is probably owing to the formation of a passive layer on the PANI interface. ${ }^{49}$ Based on the equivalent circuit models in the insets of Fig. 7(c) and (d), the electrode resistance data is shown in Table S2 as the ESI. $\dagger$

By synthetically analyzing the results of Fig. 5, 6 and 7, it is obtained that appropriate PANI coating has pinning effect for sulfur, which can enhance the utilization of the active mass and improve the cycling stability and the coulombic efficiency of the composites at different current rates.

\section{Conclusions}

In this work, the Sep/CNT/S@PANI-I, II and III composites material were obtained by using mechanical mixing, vacuum heat treatment and chemical oxidation methods in turn. Owing to the stable network structure of Sep/CNT/S composites with PANI coating, the cycling performance of the Sep/CNT/S composites with PANI coating are better than that of Sep/ $\mathrm{CNT} / \mathrm{S}$ composite at 2C rate, and Sep/CNT/S@PANI-II cathode shows the best capacity, cyclic and rate performance, with first specific capacity about $1100 \mathrm{~mA} \mathrm{~h} \mathrm{~g}^{-1}$ at 2C current density, and keeping about $650 \mathrm{~mA} \mathrm{~h} \mathrm{~g}{ }^{-1}$ after 300 cycles. With optimized surface modification of PANI coating, the initial capacity increased $37.5 \%$ and the corresponding coulombic efficiency at 2C discharge rate increased from $85 \%$ to $93 \%$ compared with the composite without PANI coating. The sepiolite and sulfur raw materials are abundant and inexpensive, and the manufacturing process is simple, making the system promising for the commercialization of lithium-sulfur batteries.

\section{Conflicts of interest}

There are no conflicts to declare.

\section{Acknowledgements}

This work was financially supported by the support from the National Key Research and Development Program of China (2016YFA0201001), National Natural Science Foundation of China (11627801 and 11472236), the National Training Program of Innovation and Entrepreneurship for Undergraduates (201510530004) and Engineering Research Center of Nano-Geo Materials of Ministry of Education of China University of Geosciences (NGM2018KF008).

\section{References}

1 Y. Fu, A. Manthiram and Y. S. Su, Acc. Chem. Res., 2013, 46, 1125.

2 J. Kim, D. J. Lee, H. G. Jung, Y. K. Sun, J. Hassoun and B. Scrosati, Adv. Funct. Mater., 2013, 23, 1076.

3 M. A. Pope and I. A. Aksay, Adv. Energy Mater., 2015, 5, 1500124.

4 X. Fang and H. Peng, Small, 2015, 11, 1488.
5 Y. Sun, Z. W. Seh, Q. Zhang and Y. Cui, Chem. Soc. Rev., 2016, 45, 5605.

6 S. Zheng, Y. Wen, Y. Zhu, Z. Han, J. Wang, J. Yang and C. Wang, Adv. Energy Mater., 2014, 4, 1400482.

7 C. Zu, L. Li, J. Guo, S. Wang, D. Fan and A. Manthiram, J. Phys. Chem. Lett., 2016, 7, 1392.

8 W. Hua, Z. Yang, H. Nie, Z. Li, J. Yang, Z. Guo, C. Ruan, X. Chen and S. Huang, ACS Nano, 2017, 11, 2209.

9 N. Xu, T. Qian, X. Liu, J. Liu, Y. Chen and C. Yan, Nano Lett., 2017, 17, 538.

10 A. F. Hofmann, D. N. Fronczek and W. G. Bessler, J. Power Sources, 2014, 259, 300.

11 H. Al Salem, G. Babu, C. V. Rao and L. M. Arava, J. Am. Chem. Soc., 2015, 137, 11542.

12 J. Bruckner, S. Thieme, A. Meier, I. Bauer, K. Gruber, J. Kaspar, A. Helmer, H. Althues, M. Schmuck and S. Kaskel, J. Mater. Chem. A, 2015, 3, 3808.

13 Y. Qu, Z. Zhang, X. Zhang, G. Ren, X. Wang, Y. Lai, Y. Liu and J. Li, Electrochim. Acta, 2014, 137, 439.

14 F. Wu, A. Magasinski and G. Yushin, J. Mater. Chem. A, 2014, 2,6064 .

15 S. Jiang, Z. Zhang, X. Wang, Y. Qu, Y. Lai and J. Li, RSC Adv., 2013, 3, 16318.

16 S. Lu, Y. Chen, X. Wu, Z. Wang, L. Lv, W. Qin and L. Jiang, RSC Adv., 2014, 4, 18052.

17 J. Liu, B. Liu, C. Wang, Z. Huang, L. Hu, X. Ke, L. Liu, Z. Shi and Z. Guo, J. Alloys Compd., 2017, 718, 373.

18 M. Wang, W. Wang, A. Wang, K. Yuan, L. Miao, X. Zhang, Y. Huang, Z. Yu and J. Qiu, Chem. Commun., 2013, 49, 10263.

19 Y. Li, L. Yuan, Z. Li, Y. Qi, C. Wu, J. Liu and Y. Huang, RSC $A d v .$, 2015, 5, 44160.

20 J. Rao, R. Xu, T. Zhou, D. Zhang and C. Zhang, J. Alloys Compd., 2017, 728, 376.

21 X. Tao, J. Wang, C. Liu, H. Wang, H. Yao, G. Zheng, Z. W. Seh, Q. Cai, W. Li, G. Zhou, C. Zu and Y. Cui, Nat. Commun., 2016, 7, 11203.

22 Q. Li, C. Zhou, Z. Ji, B. Han, L. Feng and J. Wu, J. Mater. Chem. A, 2015, 3, 7241.

23 Y. Zhang, K. Li, H. Li, Y. Wang, Y. Peng, S. Lin, B. J. Hwang and J. Zhao, J. Alloys Compd., 2017, 729, 331.

24 N. W. Li, Y. X. Yin and Y. G. Guo, RSC Adv., 2016, 6, 617.

25 J. Wang, K. Yue, X. Zhu, K. L. Wang and L. Duan, PCCP Phys. Chem. Chem. Phys., 2016, 18, 261.

26 J. H. Kim, K. Fu, J. Choi, K. Kil, J. Kim, X. Han, L. Hu and U. Paik, Sci. Rep., 2015, 5, 8946.

27 G. Ma, Z. Wen, J. Jin, Y. Lu, K. Rui, X. Wu, M. Wu and J. Zhang, J. Power Sources, 2014, 254, 353.

28 N. Nakamura, T. Yokoshima, H. Nara, T. Momma and T. Osaka, J. Power Sources, 2015, 274, 1263.

29 Y. Su, F. Li and J. Zhao, PCCP Phys. Chem. Chem. Phys., 2016, 18, 25241.

30 J. Pan, C. Wu, J. Cheng, Y. Pan, Z. Ma, S. Xie and J. Li, J. Power Sources, 2015, 293, 527.

31 X. H. Huang, J. P. Tu, X. H. Xia, X. L. Wang and J. Y. Xiang, Electrochem. Commun., 2008, 10, 1288.

32 Y. An, P. Wei, M. Fan, D. Chen, H. Chen, Q. Ju, G. Tian and K. Shu, Appl. Surf. Sci., 2016, 375, 215. 
33 X. Liang, Y. Xu, G. Sun, L. Wang, Y. Sun, S. Yang and Q. Xu, Chem. Eng. J., 2011, 174, 436.

34 L. Xiao, Y. Cao, J. Xiao, B. Schwenzer, M. H. Engelhard, L. V. Saraf, Z. Nie, G. J. Exarhos and J. Liu, Adv. Mater., 2012, 24, 1176.

35 D. F. Acevedo, C. R. Rivarola, M. C. Miras and C. A. Barbero, Electrochim. Acta, 2011, 56, 3468.

36 M. Trchová, I. Šeděnková, E. Tobolková and J. Stejskal, Polym. Degrad. Stab., 2004, 86, 179.

37 S. Sathiyanarayanan, S. S. Azim and G. Venkatachari, Electrochim. Acta, 2007, 52, 2068.

38 L. Jin, X. Huang, G. Zeng, H. Wu and M. Morbidelli, Sci. Rep., 2016, 6, 32800.

39 L. G. J. E. P. Barrett and P. P. Halenda, J. Am. Chem. Soc., 1951, 73, 373.

40 S. E. Cheon, K. S. Ko, J. H. Cho, S. W. Kim, E. Y. Chin and H. T. Kim, J. Electrochem. Soc., 2003, 150, A796.
41 X. Ji and L. F. Nazar, J. Mater. Chem., 2010, 20, 9821.

42 Z. Ma, S. Dou, A. Shen, L. Tao, L. Dai and S. Wang, Angew. Chem., Int. Ed. Engl., 2015, 54, 1888.

43 A. G. H. Yamin, J. Penciner, Y. Sternberg and E. Peled, J. Electrochem. Soc., 1988, 135, 1045.

44 W. L. Y. Mi, Q. Wang, J. Jiang, G. W. Brudvig, H. Zhou and H. Wang, J. Mater. Chem. A, 2017, 5, 23.

45 G. C. Li, G. R. Li, S. H. Ye and X. P. Gao, Adv. Energy Mater., 2012, 2, 1238.

46 Z. Deng, Z. Zhang, Y. Lai, J. Liu, J. Li and Y. Liu, J. Electrochem. Soc., 2013, 160, A553.

47 K. Xie, W. Wei, H. Yu, M. Deng, S. Ke, X. Zeng, Z. Li, C. Shen, J. g. Wang and B. Wei, RSC Adv., 2016, 6, 35746.

48 Z. Zhang, L. L. Kong, S. Liu, G. R. Li and X. P. Gao, Adv. Eng. Mater., 2017, 7, 1602543.

49 X. Zhao, H. J. Ahn, K. W. Kim, K. K. Cho and J. H. Ahn, J. Phys. Chem. C, 2015, 119, 7996. 